\title{
Sensitivity analysis of a municipal wastewater treatment plant model
}

\author{
Pawet Król ${ }^{1, *}$, Alberto Gallina ${ }^{1}$, Michał Lubieniecki ${ }^{1}$, Tadeusz $\mathrm{Uhl}^{1}$, and Tadeusz Żaba ${ }^{2}$ \\ ${ }^{1}$ AGH University of Science and Technology, Al. Mickiewicza 30, 30-59 Kraków, Poland \\ ${ }^{2}$ MPWIK S.A. w Krakowie, Senatorska 1, 30-106 Kraków, Poland
}

\begin{abstract}
Waste management is a crucial process to keep the environment in wholesome conditions. The environmental impact of solid waste and wastewater is reduced through construction of appropriate disposal installations. The objective of wastewater treatment in biological reactors is to control the process of biomaterial growth by aerating the sewage content. The process is complex, as depending on a plenty of parameters. In the last decades an effective numerical model, called the Activated Sludge Model (ASM), has been proposed for describing the biological process. The ASM is implemented in the Benchmark Simulation Model (BSM) that simulates the whole wastewater treatment process. The most important parameters in ASM are the kinetic and stoichiometric coefficients. The former describes rateconcentration dependence. The latter characterises the relationship between the components of chemical reactions taking place in the cleaning process. Above parameters are determined by on-site calibration and their importance is relevant during the development of numeric models. This paper aims to examine the influence of kinetic and stoichiometric parameters on the wastewater treatment process of a plant in Płaszów, Kraków. The analysis is carried out by a sample-based numerical procedure. It highlights the ASM parameters playing a major role in the treatment process. Results obtained from the analysis are important for future validation and optimisation processes.
\end{abstract}

\section{Introduction}

Waste management is a crucial process to keep the environment in wholesome conditions. Nowadays, sophisticated wastewater treatment plants (WWTPs) are built for treating sewages by biological processes. These processes are complex and the influence of their parameters on the process responses is hard to quantify numerically. Thanks to the development of numerical models describing the wastewater treatment process, systematic sensitivity analysis can be carried out. Previous research has been conducted in this field $[1,2]$. This paper proposes the utilisation of a screening method called the Morris method that involves low computational burden. This aspect is important in wastewater treatment simulations that usually are timeconsuming. The analysis is applied to the WWTP located in Płaszów, Krakow.

The municipal WWTP in Płaszów is a modern facility which treats sewage from Kraków agglomeration located in the south of Poland. It consists of 5 biological reactors supported by 10 secondary clarifiers, a sewage recirculation chamber and a blower station. In reactors sewage continually recirculates in 10 sections both in aerobic and anaerobic environment. Each reactor cooperates with two secondary clarifiers in which activated sludge is collected for further utilisation. Sewage parameters are measured during treatment by a SCADA control and monitoring system. Information about the ammonia and oxygen amount in the reactor has large importance on the treatment process control. The proposed analysis investigates the influence of a large set of treatment process parameters on the ammonia and oxygen levels. Analysis shows that only a small set of parameters really affects the levels.

The paper is structured as follows. In Section 2 parameters of the Activated Sludge Model are shortly described. Section 3 presents the Benchmark Simulation Model and its adaptation to the WWTP of Płaszów. Section 4 illustrates the sensitivity analysis. Conclusions are drawn in Section 5.

\section{ASM in waste water treatment}

The ASM models biological processes occurring in treatment by formulation of mathematical equations. The basic model, named ASM1, was published in 1987 and it was letter extended with new functionalities [3, 4]. The primary sewage characteristics such as content of inorganic and organic matter, and alkalinity are simulated. The effluent is characterised by state variables, which represent concentrations of components in the wastewater, and dynamics observed during water cleaning is described by state equations. In particular, ASM1 includes 13 state variables.

One group of variables are biodegradable components of the Chemical Oxygen Demand (COD). They are: Readily biodegradable substrate $S_{S}$; slowly

* Corresponding author: pawel.krol@agh.edu.pl 
biodegradable substrate $X_{S} ;$ Active heterotrophic biomass $X_{B, H}$; Active autotrophic biomass $X_{B, A}$. Nonbiodegradable material characterised by variables unaffected by biological action in the system: $S_{I}$ and $X_{I}$; Variable $X_{P}$ models inert particulate matter arising from biomass decay. These components are summarised in Table 1.

Table 1. Wastewater characterisation for carbonaceous components [3].

\begin{tabular}{|c|c|c|}
\hline \multirow{6}{*}{ COD } & \multirow{2}{*}{$\begin{array}{l}\text { Biodegradable } \\
\text { COD }\end{array}$} & Soluble - $S_{S}$ \\
\hline & & Particulate $-X_{S}$ \\
\hline & \multirow{2}{*}{$\begin{array}{l}\text { Non-Biodegradable } \\
\text { COD }\end{array}$} & Soluble - $S_{I}$ \\
\hline & & Particulate $-X_{I}$ and $X_{P}$ \\
\hline & \multirow{2}{*}{ Active mass COD } & Heterotrophs - $X_{B, H}$ \\
\hline & & Autotrophs - $X_{B, A}$ \\
\hline
\end{tabular}

Remaining state variables are concentration of dissolved oxygen, $S_{O}$, the alkalinity level, $S_{A L K}$, and 4 components of the Total Kjeldahl Nitrogen (TKN). These latter are: The combined nitrate and nitrite nitrogen, $S_{N O}$, which is intermediate product of nitrification; Biodegradable organic nitrogen, $X_{N D}$; Soluble biodegradable organic nitrogen, $S_{N D}$; Volumetric concentration of free and saline ammonia in dilution, $S_{N H}$. The whole set of TKN components are shown in Table 2.

Table 2. Wastewater characterisation for nitrogenous components [3].

\begin{tabular}{|c|c|c|c|}
\hline \multirow{6}{*}{ TKN } & \multicolumn{3}{|c|}{ Free $\&$ Saline ammonia $-S_{N H}$} \\
\hline & \multirow{4}{*}{$\begin{array}{l}\text { Organically } \\
\text { bound } \mathrm{N}\end{array}$} & \multirow{2}{*}{$\begin{array}{l}\text { Soluble } \\
\text { Organic N }\end{array}$} & $\begin{array}{l}\text { Nonbiodeg. N } \\
S_{N I}\end{array}$ \\
\hline & & & \multirow{2}{*}{$\begin{array}{l}\text { Biodeg. } \mathrm{N} \\
S_{N D} \text { and } X_{N D}\end{array}$} \\
\hline & & \multirow{2}{*}{$\begin{array}{l}\text { Particulate } \\
\text { organic N }\end{array}$} & \\
\hline & & & $\begin{array}{l}\text { Nonbiodeg N } \\
X_{N I} \text { and } X_{N P}\end{array}$ \\
\hline & \multicolumn{3}{|c|}{ Active mass $\mathrm{N}-X_{N B}$} \\
\hline
\end{tabular}

The treatment process itself is described by 8 processes reflecting natural transformations observed during sewage treatment. Table 3 presents all processes included in ASM1 model. State characteristics and processes are reciprocally correlated. The processes are related to the model coefficients through a set of 5 stoichiometric and 14 kinetic parameters. Stoichiometric parameters describe the relationship between the components, while kinetic - rateconcentration dependence in the process.

The former parameters are denoted by $Y_{A}, Y_{H}, f_{P}, i_{X B}$, $i_{X P} . Y_{A}$ and $Y_{H}$ are autotrophic and heterotrophic yields, respectively. $f_{P}$ is the fraction of biomass yielding particulate products that ends up as inert. Parameters $i_{X B}$,
$i_{X P}$ describe the percent of mass nitrogen in COD in biomass and in products from biomass respectively.

All process equations are described by kinetic parameters. The pool of variables is divided into groups dependent upon their influence on the process. Parameters $\mu_{H}, K_{S}, K_{O, H}, K_{N O}, b_{H}$ describe heterotrophic growth and decay. In particular, $K_{O, H}$ and $K_{N O}$ switch aerobic and anoxic growth depending on the oxygen concentration. The heterotrophic decay coefficient, $b_{H}$, is responsible for production of sludge and oxygen requirements. $\mu_{H}$ controls the maximum oxygen utilisation rate. $K_{S}$ is a switching function between first order and zero order kinetics for heterotrophic biomass growth and substrate removal. Parameters $\mu_{A}, K_{N H}, b_{A}$, $K_{O, A}$ describe autotrophic growth and decay. Parameter $K_{O, A}$ stops nitrification, when dissolved oxygen level is too low. Decay coefficient $b_{A}$ describes process of autotrophic decay. Parameter $\mu_{A}$ is a maximum specific growth rate of autotrophic biomass. Parameter $K_{N H}$ is an ammonia half saturation coefficient for autotrophs. Value of $\eta_{g}$ is a correction factor for anoxic growth of heterotrophs. Parameter $\eta_{h}$ is a correction factor for anoxic hydrolysis of slowly biodegradable organic matter. Parameter $k_{a}$ is the value of the ammonification rate. Parameters $k_{h}$ and $K_{X}$ are responsible for hydrolysis. $k_{h}$ is the maximum specific hydrolysis rate. Half saturation coefficient $K_{X}$ evaluates hydrolysis of slowly biodegradable organic matter.

Table 3. Processes in ASM numeric models.

\begin{tabular}{|l|l|}
\hline $\mathrm{Nr}$ & Process \\
\hline 1 & Aerobic growth of heterotrophs \\
\hline 2 & Anoxic growth of heterotrophs \\
\hline 3 & Aerobic growth of autotrophs \\
\hline 4 & Decay of heterotrophs \\
\hline 5 & Decay of autotrophs \\
\hline 6 & Ammonification of soluble organic nitrogen \\
\hline 7 & Hydrolysis of entrapped organics \\
\hline 8 & Hydrolysis of entrapped organic nitrogen \\
\hline
\end{tabular}

According to [5] there are characteristic values for $Y_{A}, b_{A}, f_{P}, i_{X B}, i_{X P}, K_{O, H}, K_{N O}$ and $K_{O, A}$. Conversely, $Y_{H}$, $\mu_{A}, K_{N H}, b_{H}, \eta_{g}, \eta_{h}, \mu_{H}, K_{S}, k_{h}, K_{X}$ and $k_{a}$ are strictly dependent on the particular operating conditions. In [3] authors suggest that parameters are influenced by change of temperature (studied $10^{\circ} \mathrm{C}$ and $20^{\circ} \mathrm{C}$ ). Sin [6] proposes three different classes of uncertainty for the parameter values (class $1-5 \%$, class $2-25 \%$, class $3-50 \%$ ).

Some works have been undertaken for the tuning of these parameters to specific WWTPs. For instance, Lee and Kim propose standardised model calibration method for the optimal parameter estimation of ASM [7]. Liwarska and Ladakowicz present methods aiming at the determination of selected parameters of activated sludge [8]. The work in [9] presents evaluation of parameters in ASM1 model of municipal-industrial wastewater plant. 
In [10] the ASM1 model of Iranian waste water plant is presented. Elshorbagy and Shawaqfah propose a tuned ASM1 dynamic simulation in United Arab Emirates [11].

\section{BSM1 in Płaszów WWTP}

The ASM is commonly implemented in the Benchmark Simulation Model, BSM. This latter is a numerical framework that describes the entire wastewater treatment process of a WWTP. It was developed by a research team in University of Lund [12] that released it as a Matlab/Simulink implementation. BSM1 is the first version of BSM model.

BSM1 and ASM were exploited for describing the wastewater treatment of the WWTP in Płaszów. The Simulink diagram of the adapted BSM1 is exhibited in Fig. 1. As visible in the figure, during normal exploitation the reactor has five, non-aerated sections (KPD, a dephosphatation section KDF, denitrification sections KDN1, KDN2, KDN3 and a deoxygenated section $\mathrm{KO}$ ) and 5 aerated sections (aerobic nitrification sections KN1, KN2, KN3, KN4). Structural parameters of the model, i.e. volume of tanks, proportion of inner and outer recirculation, oxygen and ammonia sensors are set to values supplied in the WWTP documentation. Dissolved oxygen, the parameter that is crucial during wastewater treatment, is measured in all sections. Expected content of dissolved oxygen depends on the level of ammonia measured in KN4 (last nitrification section). Authors implemented in the model the algorithm existing in Płaszów WWTP where the expected amount of dissolved oxygen depends nonlinearly on the concentration of dissolved ammonia.

For the purposes of the research presented in this paper a 7-day long signal of the influent was considered in computer simulations. The signal is taken from SCADA measurements of the incoming sewage and it is depicted in Fig. 2. The 13 influent parameters describing the influent quality are assumed to be constant, although they are, in fact, subjected to variations. This assumption is justified by the fact that parameter values are unknown and that the research aims to examine the influence of the process parameters only. The constant values assumed for the influent parameters are listed in Table 4 .
Table 4. Constant influent parameters in Płaszów WWTP.

\begin{tabular}{|c|c|c|}
\hline Parameter & Unit & Value \\
\hline Soluble inert organic matter $S_{I}$ & $\mathrm{gCOD} / \mathrm{m}^{3}$ & 30 \\
\hline Readily biodegradable substrate $S_{S}$ & $\mathrm{gCOD} / \mathrm{m}^{3}$ & 69.5 \\
\hline Particulate inert organic matter $X_{I}$ & $\mathrm{gCOD} / \mathrm{m}^{3}$ & 51.2 \\
\hline Slowly biodegradable substrate $X_{S}$ & $\mathrm{gCOD} / \mathrm{m}^{3}$ & 202.3 \\
\hline Active heterotrophic biomass $X_{B, H}$ & $\mathrm{gCOD} / \mathrm{m}^{3}$ & 28.17 \\
\hline Active autotrophic biomass $X_{B, A}$ & $\mathrm{gCOD} / \mathrm{m}^{3}$ & 0 \\
\hline $\begin{array}{l}\text { Particulate products from biomass } \\
\text { decay } X_{P}\end{array}$ & $\mathrm{gCOD} / \mathrm{m}^{3}$ & 0 \\
\hline Oxygen $S_{o}$ & $\mathrm{gO}_{2} / \mathrm{m}^{3}$ & 0 \\
\hline Nitrate and nitrite nitrogen $S_{N O}$ & $\mathrm{gNO}^{3} / \mathrm{m}^{-3}$ & 0 \\
\hline $\mathrm{NH}_{4}^{+}+\mathrm{NH}_{3}$ nitrogen $\mathrm{S}_{\mathrm{NH}}$ & $\mathrm{gNH}^{3} / \mathrm{m}^{-3}$ & 31.56 \\
\hline $\begin{array}{c}\text { Soluble biodegradable organic } \\
\text { nitrogen } S_{N D}\end{array}$ & $\mathrm{gN} / \mathrm{m}^{-3}$ & 6.95 \\
\hline $\begin{array}{c}\text { Particulate biodeg. organic } \\
\text { nitrogen } X_{N D}\end{array}$ & $\mathrm{gN} / \mathrm{m}^{-3}$ & 10.59 \\
\hline Alkalinity $S_{A L K}$ & $\mathrm{~mol} / \mathrm{m}^{3}$ & 7 \\
\hline
\end{tabular}

Sewage flow in Płaszów WWTP

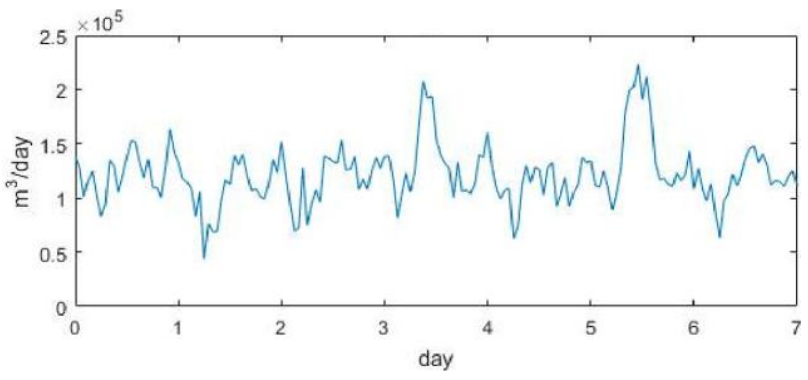

Fig. 2. Sewage influent based on SCADA measurements.

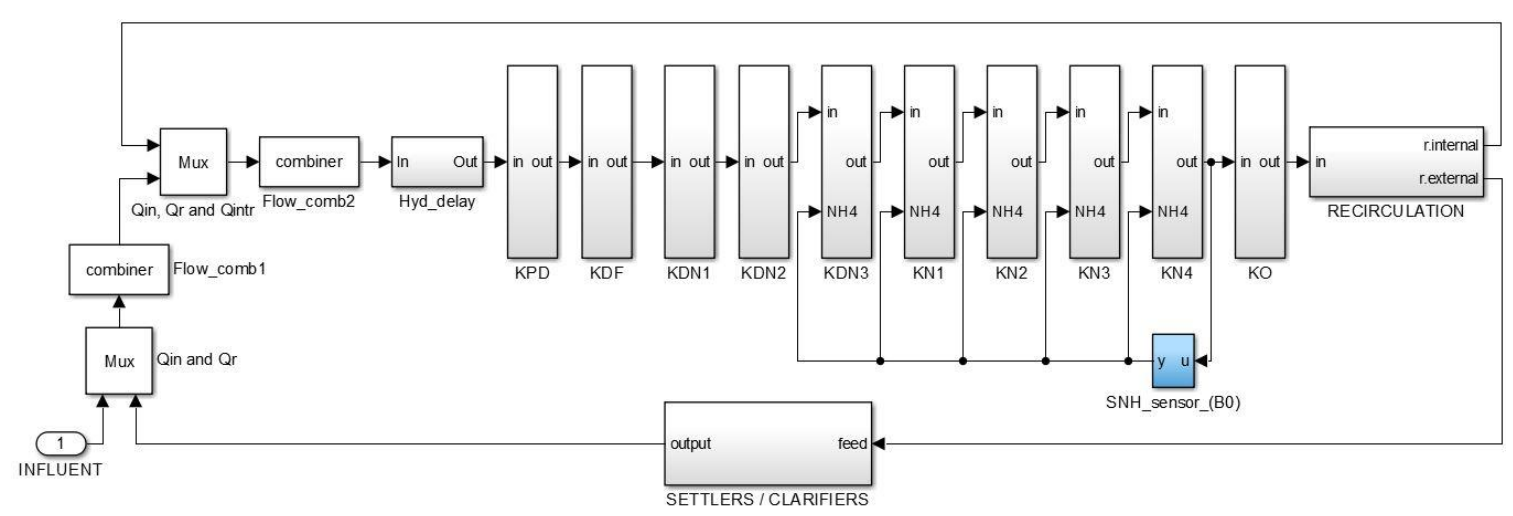

Fig. 1. BSM1 model of Płaszów WWTP (Matlab/Simulink). 


\section{Sensitivity analysis}

Parameter screening has been carried out to assess the influence of the stoichiometric and kinetic parameters on the BSM1 response, namely the average value of $\mathrm{NH}_{4}$ and $\mathrm{O}_{2}$ levels in the reactor sections. For this purpose, the authors suggest the use of the Morris method [13]. The method performs a global sensitivity analysis where parameters are changed over their entire range of uncertainty. The assumed variability ranges, based on [6] and [14], are given in Tab. 5. The Morris method involves the creation of a regular hyper-grid of coded input variables defined within the assumed range of variability. The resolution of the hyper-grid is assumed by the researcher. In this application the grid uses 15 levels for each variable. Since the variables are coded, they always vary between 0 and 1, with 0 corresponding to the minimum value of the physical parameter and 1 the maximum one. Next, an assumed number of trajectories on the hyper-grid are created. The trajectory is a path described by sequential computer simulations run at particular grid points. Each path is generated randomly, under the condition that parameters are changed one-at-the-time over the grid, by moving always the same amount of grid levels. Thus, the number of simulations in a trajectory equals to the number of variables plus one. Considering that the current application has 19 input variables and that 10 different trajectories were created, 200 simulations were run altogether. Changes of physical values of parameters for a single trajectory are depicted in Fig. 3. In order to examine the impact of parameters on the model response their elementary effects are to be evaluated. The elementary effect of a parameter is the amount of change of the response when the corresponding parameter is changed in the trajectory. Thus, as many elementary effects as the number of trajectories are calculated for every parameter. Finally, the mean and standard deviation of over the set of elementary effects provides information about the global influence of the parameter and its non-linear dependence on the response, respectively.

Results of the analysis are presented in the diagram in Fig. 4. Since the section KN4 is of major importance remember that ammonia SCADA measurements used in the control system are from this section - detailed results for KN4 are presented in Fig. 5. The analysis shows that ammonia half-saturation coefficient for autotrophic biomass $\left(K_{N H}\right)$ has a decisive role in the wastewater treatment. Indeed, the parameter directly impacts aerobic growth of autotrophs. It is also worth noting that the change in the half saturation coefficient $K_{N H}$ for autotrophs has the highest impact comparing with other half heterotrophic saturation coefficients $\left(K_{N O}, K_{O, H}\right)$. Moreover, it should be observed that the means and standard deviations of elementary effects for both $\mathrm{NH}_{4}$ and $\mathrm{O}_{2}$ responses show the same trend. It means that the process is in general non-linear, as expected due to the complexity of the biological process. Finally, sensitivity diagrams say that several process parameters are not playing important role in the production of $\mathrm{NH}_{4}$ and $\mathrm{O}_{2}$. This result has large practical impact in system control and very useful for parameter reduction in view of optimisation analyses.

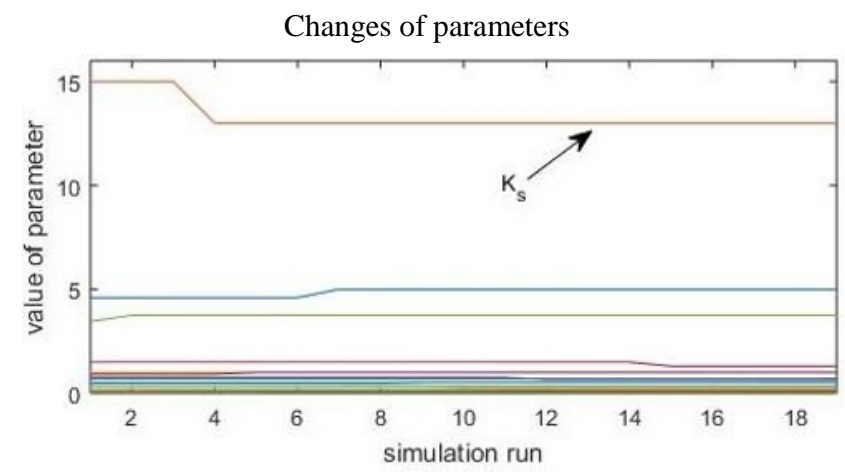

Fig. 3. Changes of parameters for one trajectory in screening analysis.

Table 5. Stoichiometric and kinetic parameters in WWTP simulation - proposed range of values.

\begin{tabular}{|c|c|c|c|c|}
\hline Parameter & Unit & Min & $\begin{array}{l}\text { St. } \\
\text { Val. }\end{array}$ & $\operatorname{Max}$ \\
\hline Autotrophic yield $Y_{A}$ & $\mathrm{gCOD} / \mathrm{gN}$ & 0.23 & 0.24 & 0.25 \\
\hline Heterotrophic yield $Y_{H}$ & $\begin{array}{l}\mathrm{gCOD} / \\
\mathrm{gCOD}\end{array}$ & 0.64 & 0.67 & 0.70 \\
\hline $\begin{array}{l}\text { Fraction of biomass } \\
\text { yielding part. products }\end{array}$ & - & $\begin{array}{l}0.01 \\
5\end{array}$ & 0.08 & 0.2 \\
\hline $\begin{array}{l}\text { Mass N/mass COD in } \\
\text { biomass } i_{X B}\end{array}$ & $\mathrm{gN} / \mathrm{gCOD}$ & 0.04 & 0.08 & 0.12 \\
\hline $\begin{array}{l}\text { Mass N/mass COD in } \\
\text { products from biomass }\end{array}$ & $\mathrm{gN} / \mathrm{gCOD}$ & 0.05 & 0.06 & 0.07 \\
\hline $\begin{array}{l}\text { Heterotrophic max. } \\
\text { specific growth rate }\end{array}$ & day $^{-1}$ & 3.0 & 4.0 & 5.0 \\
\hline $\begin{array}{l}\text { Half-saturation } \\
\text { coefficient (hsc) for }\end{array}$ & $\mathrm{gCOD} / \mathrm{m}^{3}$ & 5.0 & 10.0 & 15.0 \\
\hline $\begin{array}{l}\text { Oxygen hsc for } \\
\text { heterotrophs } K_{O, H}\end{array}$ & $\mathrm{gO}_{2} / \mathrm{m}^{3}$ & 0.1 & 0.2 & 0.3 \\
\hline $\begin{array}{l}\text { Nitrate hsc }{ }^{\mathrm{a}} \\
\text { denitrifying }\end{array}$ & $\mathrm{gNO}_{3} / \mathrm{m}^{3}$ & 0.25 & 0.5 & 0.75 \\
\hline $\begin{array}{l}\text { Heterotrophic decay } \\
\text { rate } b_{H}\end{array}$ & day $^{-1}$ & 0.29 & 0.3 & 0.32 \\
\hline $\begin{array}{l}\text { Corr. factor for anoxic } \\
\text { heterotrophs growth }\end{array}$ & - & 0.6 & 0.8 & 1.0 \\
\hline $\begin{array}{l}\text { Correction factor for } \\
\text { anoxic hydrolysis } \eta_{h}\end{array}$ & - & 0.6 & 0.8 & 1.0 \\
\hline $\begin{array}{l}\text { Max. specific } \\
\text { hydrolysis rate } k_{h}\end{array}$ & $\begin{array}{l}\mathrm{gX}_{\mathrm{S}} / \mathrm{gX}_{\mathrm{B}} \\
\mathrm{HCODda}\end{array}$ & 2.25 & 3.0 & 3.75 \\
\hline $\begin{array}{l}\text { Hydrolysis hsc of } \\
\text { slowly biodeg. }\end{array}$ & $\begin{array}{l}\mathrm{gX}_{\mathrm{S}} / \mathrm{gX} \mathrm{B}_{\mathrm{B}} \\
\mathrm{HCOD}\end{array}$ & $\begin{array}{l}0.07 \\
5 \\
\end{array}$ & 0.1 & $\begin{array}{l}0.12 \\
5 \\
\end{array}$ \\
\hline $\begin{array}{l}\text { Autotrophic max. } \\
\text { specific growth rate } \mu_{A}\end{array}$ & day $^{-1}$ & 0.48 & 0.5 & 0.53 \\
\hline $\begin{array}{l}\text { Ammonia hsc for } \\
\text { autotrophs } K_{N H}\end{array}$ & $\begin{array}{l}\mathrm{gNH}_{3} / \\
\mathrm{m}^{3}\end{array}$ & 0.5 & 1.0 & 1.5 \\
\hline $\begin{array}{l}\text { Autotrophic decay rate } \\
b_{A}\end{array}$ & day $^{-1}$ & 0.04 & 0.05 & 0.06 \\
\hline $\begin{array}{l}\text { Oxygen hsc for } \\
\text { autotrophs } K_{O, A}\end{array}$ & $\begin{array}{l}\mathrm{gO}_{2} / \\
\mathrm{m}^{3}\end{array}$ & 0.3 & 0.4 & 0.5 \\
\hline $\begin{array}{l}\text { Ammonification rate } \\
k_{a}\end{array}$ & $\begin{array}{l}\mathrm{m}^{3} / \mathrm{gCO} \\
\text { D/day }\end{array}$ & 0.03 & 0.05 & 0.08 \\
\hline
\end{tabular}


Mean for $\mathrm{O}_{2}$

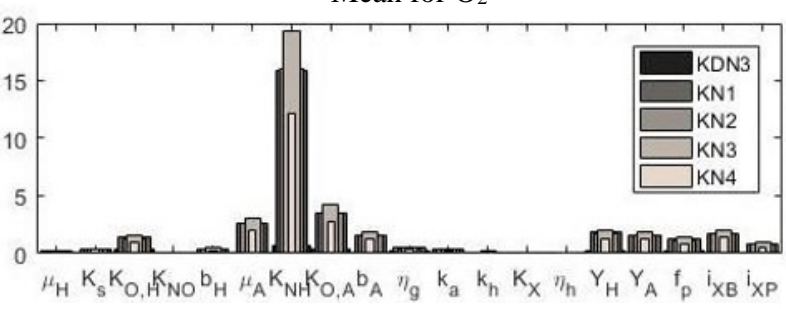

Standard deviation for $\mathrm{O}_{2}$

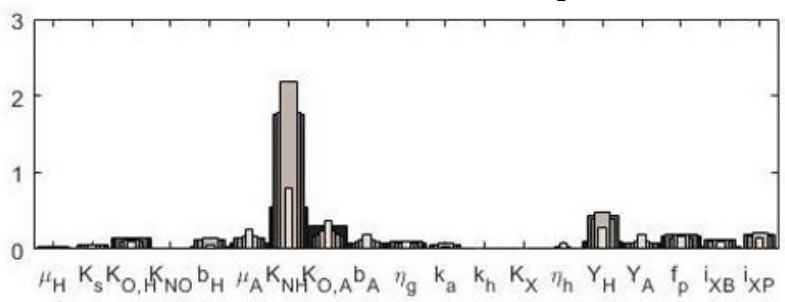

Fig. 4. Mean and standard deviation of oxygen $\mathrm{O}_{2}$ in aerated sections of ASM1 model of Płaszów WWTP.
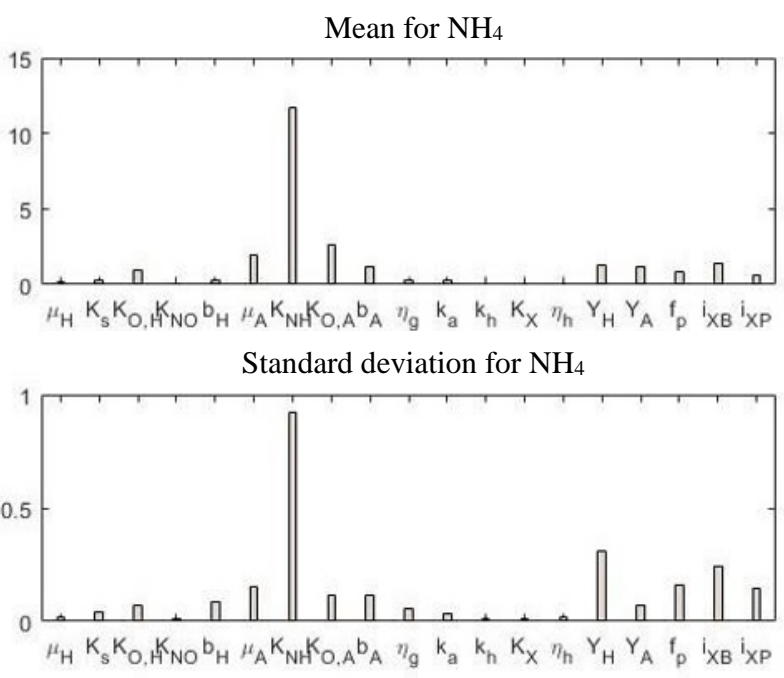

Fig. 5. Mean and standard deviation of ammonia NH4 in KN4 of ASM1 model of Płaszów WWTP.

\section{Conclusions}

In the paper, the influence of chemical process parameter on process outputs for the Płaszów WWTP has been presented. The analysis has been done using an efficient global parameter screening procedure. The screening analysis allows to reduce uncertainty of the model by prioritisation of its sources.

The results highlighted high non-linearity of the model and indicated that the ammonia half saturation coefficient $K_{N H}$ is the most influent on oxygen and ammonium levels in the reactor designed in BSM1 implementation of ASM1 model.

\section{References}

1. G. Sin, K. V. Gernaey, M. B. Neumann, M. C. M. van Loosdrecht, W. Gujer, Water Res. 45, (2011)

2. X. Flores-Alsina, K. V. Gernaey, U. Jeppsson, 8th IWA Symposyum on Systems Analysis and Integrated Assessment, WATERMAX 2011, (2011)

3. U. Jeppsson, Components 1, 1 (1996)

4. P. Ingildsen, Realising full-scale control in wastewater treatment systems using in situ nutrient sensors, vol. PhD. (2002)

5. M. Henze, W. Gujer, T. Mino, M. C. M. van Loosdrecht, IWA Publ. (2000).

6. G. Sin, K. V. Gernaey, M. B. Neumann, M. C. M. van Loosdrecht, W. Gujer, Water Res. 43, 11, (2009)

7. W. Y. Lee, M. H. Kim, C. K. Yoo, 2008 Int. Conf. Control. Autom. Syst. ICCAS 2008 (2008)

8. E. Liwarska-Bizukojc, S. Ledakowicz, Environ. Prot. Eng. 37, 3, (2011).

9. B. Petersen, K. Gernaey, M. Henze, and P. A. Vanrolleghem, J. Hydroinformatics 4, 1 (2002)

10. F. Mohamadi, S. Rahimi, Curr. World Environ. 10, 1 (2015)

11. W. E. Elshorbagy and M. Shawaqfah, Desalin. Water Treat. 3 (2014)

12. J. Alex Lutedx, TEIE-7229, 1 (2008)

13. P. Ekström, Master's (2005)

14. S. Sharifi, S. Murthy, I. Takács, and A. Massoudieh, Water Res. 50 (2014). 